Kohl: a Journal for Gender and Body Research

Vol. 1, No. 2 (Winter 2015)

\title{
Fantasy, Mysticism, and Eroticism in Raja Alem's Fatma
}

\author{
Ghadir K. Zannoun
}

\begin{abstract}
:
This paper is a close reading of Raja Alem's 2005 novel, Fatma: A Novel of Arabia. I argue that Alem depicts the erotic in ways similar to Audre Lorde's definition - as a doorway to self-fulfillment and in honor of the "fullness" of the erotic's depth of feelings. The Saudi Arabian writer employs the fantastic, which has been used by writers to express feminist politics, to give textual embodiment to the relationship between the erotic, self-actualization, and women's empowerment, central to which is self-knowledge and self-discovery. Alem suggests that a deeper knowledge of the self can open women to unlimited possibilities of being and perception, including a closer relationship to the natural and the supernatural worlds. Alem thus presents a female mythology that creates an alternate reality and undermines the binaries of patriarchal thinking, such as the corporeal/transcendent, the human/nonhuman, man/woman, and nature/culture.
\end{abstract}


That night I watched the window sill, watched the moon dry the blood on the tail, dreamed rattler fangs filled my mouth, scales covered my body. In the morning I saw through snake eyes, felt snake blood course through my body. The serpent, mitono, my animal counterpart. I was immune to its venom. Forever, immune.

- Gloria Anzaldúa (48)

Raja Alem's Fatma: A Novel of Arabia, exemplifies what Sabry Hafez describes as - borrowing Elaine Showalter's term ${ }^{1}$ - "female writing," which represents a complex stage in feminism (158). Unlike feminist writing, which focuses primarily on attempting to subvert the patriarchal system, female writing emerges from the notion that this subversion is futile. Instead, it contends that women's efforts should focus on filling the gap and counteracting this system by asserting their presence through the representation of the body, unofficial history, women's history, non-binary realities, and perception (Hafez 170-75). In this novel, Alem one of Saudi Arabia's contemporary and most prolific and prominent women writers, and a joint winner of the 2011 Arabic Booker Prize ${ }^{2}$ - reclaims the Arabian Peninsula's folk and mythical tales by placing women's histories in the forefront. Alem offers an alternate reality where the limitations, restrictions, hierarchies, and repressions of the novel's real world are suspended through other forms of knowledge, language, and identity. More specifically, through her use of the fantastic, Alem depicts the liberating quality of this alternative reality through the notion of the erotic. The erotic, as Audre Lorde tells us, is often a repressed element, and it is a power or a source that expands self-knowledge, insight, feelings, and action. Lorde explains the erotic as "an internal sense of satisfaction to which, once we have experienced it, we know we can aspire," and after which we demand "no less of ourselves" (209). Therefore, once this need for the fullness of being is embraced, the journey of self-discovery and self-understanding begins, resulting in more expansive ways of perception that undermine existing binaries and hierarchies.

Alem mobilizes the fantastic to envision what women's lives would look like through these expanded ways of living, seeing, and feeling. This paper thus highlights how the erotic is an element central to the fantastic, allowing women of past times to connect differently to the world around them (the human, the natural, and the spiritual), and subsequently to live more powerful lives. In the contemporary period in which the novel is situated, the erotic also becomes key to the journey of self-discovery of the main character - Fatma, as she connects to this power and to the fantastic. With elements of the supernatural merged with Sufi mysticism,

\footnotetext{
${ }^{1}$ Elaine Showalter uses the terms "female" and "feminist" writing in her typology of female literary tradition in the English novel (2001). Sabry Hafez identifies similar stages in his typology of Arab women's writing (158). There are of course alternatives to white feminist writings and their trajectory. Feminists who are not from a European background have established or have sought to delineate their own feminist and literary traditions. African American writer Alice Walker, for example, coined the term "womanism," to point to a Black and women of color tradition contextualized in their particular history, and to expose the heterosexism and racism of dominant white feminism. See Alice Walker's In Search for Our Mother's Gardens: Womanist Prose (1983).

2 Raja Alem shared her 2011 Arabic Booker Prize for her novel The Doves' Necklace with the Moroccan writer Mohammed Achaari.
} 
Alem's novel celebrates myths and folk histories, particularly women's older folk histories and knowledge that carry these alternative realities.

Based on the definition of the fantasy's functions, this genre is the most apt for depicting the themes that Alem's novel explores. ${ }^{3}$ Fantasies urge a revision of the social, natural, and transcendent realities as well as their underlying modes of perception. This revision permits us to see the world anew by inviting us to view it differently and to envision realities better anchored in social justice (Brawley 12). I read Fatma as a fantasy of revision, as opposed to the fantasy of illusion and of vision. According to Kathryn Hume, "Literature of revision allows people to escape from their culture's imperfect systems of authority based on reason, and lets them experience other possibilities for ordering experience, whether religious or utopian" (qtd. in Brawley 7). It urges readers towards a "rediscovery" of reality, not an escape from it, in its deepest religious or utopian form (8). In re-visioning culture, fantasy "traces the unsaid and unseen of culture: that which has been silenced, made invisible, covered over and made 'absent"' (Jackson 4). Similarly, Fatma offers readers the possibility of re-visioning their experiences in order to reclaim and reinterpret silenced, marginalized, and demonized cultural elements of the Arabian Peninsula, including unofficial histories and their underlying forms of knowledge and symbols. Therefore, not only does Alem undermine the traditional binaries and hierarchies of the corporeal/transcendent, human/nonhuman, man/woman, and nature/culture, but she also writes the repressed elements of culture back into history.

\section{Fatma's Initiation into the Erotic: A Reclamation of "Feminine" Symbols}

In this novel, Fatma, the once simple girl from the modern Arab Peninsula, is married to the abusive snakehandler, Sajir. From the very beginning of their marriage and for twenty years, Sajir remains detached from his wife and denies her the right to feel, which reduces their marriage to a strictly physical relationship devoid of sensuality and love. Sometime after their marriage, Fatma is bitten by one of Sajir's very poisonous snakes; though it almost kills her, the snakebite also makes her experience erotic sensations. ${ }^{4}$ As a result, Fatma embarks on an inward journey of healing through the erotic. As she grows more aware of her body, inner self, and abilities, she undergoes a gradual but empowering transformation into a complex and powerful woman. Fatma's self-knowledge leads to an expanded understanding and multiple perceptions: she becomes able to connect differently to people, to the natural and animal world, as well as to the spiritual world. More importantly, Fatma's awakened perceptions allow her to recall the stories of her powerful grandmother and to be conscious of other histories that exemplify alternative ways of being, including a different way of relating to the erotic. Ultimately, Fatma reclaims these histories not only through the work of memory and orality, but through art. She embroiders these stories on her gown, or abaya, which almost becomes alive by itself.

3 The elements of the fantastic in Fatma may also be described as magic realism, a genre which portrays "fantastic elements in a real world setting" (Henituik 410-11) that has been employed by writers, including women, to centralize cultural elements, voices and points of views that have been marginalized (D'haen 200).

${ }^{4}$ Here I am using "erotic" as sexual desire but also and defined by Lorde interchangeably, and as the novel suggests, the two are very closely linked, where women's sexual feelings lead to their pursuit of self-realization and empowerment. 
By starting Fatma's journey with a bite of the snake, Alem rewrites the snake as the source of healing and transformation. In both the Judeo-Christian and the popular Arabo-Islamic traditions, the serpent is associated with the story of the fall and of original sin, symbolizing deception. Such writings, then, reclaim negative symbolism about women and endow it with new and empowering meanings (Suleiman 132). The author uses the snake based on its ancient symbolism - as a symbol of healing, the feminine, the inner self, and the hidden and unknown (Abu Yahya 259). As elaborated on later, the hidden in the novel is the inner self, which includes female eroticism. When the snake bites her, Fatma feels "delirious with pleasure" (19). It is precisely this erotic passion that Sajir sees in Fatma's eyes after she recovers from the bite, as she reveals an "unmistakable erotic twinkle in her eyes" (23). Immediately after the snake bites her, and in addition to unleashing desire in her body, Fatma's voice is liberated. She unintentionally lets out a powerful sound that confuses Sajir: he could not tell "if the scream came from his wife or the snake," as it was "something between a shriek and a hiss" (19).

As Luce Irigaray argues, female multifaceted eroticism is not acknowledged by the Law of the Father (28). Based on this definition, Alem is also suggesting that healing can only happen through the multiple elements of the erotic. Similarly, Gloria Anzaldúa compares the ability to live fully and to move freely, which women are very often denied, to the writhing movement of the serpent. She writes, "[b]locked, immobilized, we can't move forward, can't move backwards. That writhing serpent movement, the very movement of life, swifter than lightning, frozen" (20-21). Whereas Fatma was emotionally and physically immobilized, the snake, a symbol of mobility initiates her "imaginary" journey. It requires such a near-death experience to propel her into a journey that takes her to different places where her "real" world's hierarchies and limitations are suspended, and where she is able not only to feel, but to refine her feelings and sensibilities. More importantly, she herself becomes a serpent-woman, seeing through "snake eyes" and moving like a serpent, as Anzaldúa writes.

Whereas the novel explores the erotic in the lives of women in the past and contemporarily reclaimed, it also presents what a life without it would look and feel like for Fatma. The debilitating, sexually abusive relationship that Sajir imposes on Fatma is oppressive, especially that it lacks any sensuality and connection to their inner worlds. Alem compares this lack of self-knowledge, which leads to a lack of understanding of others, to wearing a mask, making real communication impossible. Hence, Sajir remains detached from his wife as "night after night, Fatma faced that mask. Twenty years she fed it, washed its rags and went to bed with it. Twenty years of being treated like a thing, trampled" (4). Such a relationship is, predictably, dehumanizing for Fatma as well. Indeed, Alem chooses to open the novel with a description of Sajir, suggesting that he is an atypical member of society. He is "possessed by blue devils," and his "blue cast" (1) can be contrasted with Fatma's later association with warm-blooded animals (76).

The narrator repeatedly hints at a link between Sajir and the modern lifestyle, especially cars, which are described as the demons of the machine age. The first night after the husband throws Fatma out on the street 
because her transformation grows more and more powerful, 5 the red cars remind Fatma of Sajir and her relationship with him, as if he was there, "pouncing on her" (4). Similarly, Fatma observes the faces of the drivers who pass her by, honking at her as she stands in the middle of the street in the middle of the night; they appear hypnotized and lacking any feeling, wearing Sajir's mask (3). In other words, Alem differentiates machine-like imagery and uprooted modernity from self-knowledge and the discovery of the erotic through ancestral figures and myths.

By contrast to her married house, Fatma's imagined spaces have positive connotations: Najran, the space to which she travels during her imaginary journey, is the geographical embodiment of an alternative fantastical reality. It is named after a real geographical area in the southern part of present-day Saudi Arabia. Previously belonging to Yemen, the area only came under the Saudi sovereignty in 1939. More importantly, the region's multiple unofficial histories are implied in the rich mythical world it embodies, as opposed to the novel's "real" world. In fact, Fatma has such a great memory of Najran that she feels overwhelmed every time she recalls it. Yet, her attachment to Najran does not represent a rejection of the modern and reinstatement of the past/present and tradition/modernity binaries, but rather an identification with an alternate reality implied in this region's myths and folk histories.

Additionally, Alem does not seek to recreate a binary of bad Arab men/Arab women victims. While Sajir represents the emotionally repressed and repressive male, Alem depicts other Arab men from the present time of the novel more favorably. Indeed, it is a Yemenite porter who comes to Fatma's rescue that night when she finds herself on the street cast out of her marriage home. The reference to Yemen here is significant as well: Yemen is the place from where Arabs originate, the area where the queen of Sheba ruled, and a symbol of prosperity. The Yemenite also represents the spiritual, which is integral to Fatma's transformation: he chants an old prayer that she describes as "ancient" (4). It is a prayer reminiscent of Islamic mysticism and Sufism in particular, aspects that I will address in the final section of this paper. Moreover, Fatma feels reassured by the young man who gets out of his car to help her when he mistakenly thinks that the porter is following her. Though young in age, Fatma perceives that something about the man "seem[s] to have awoken from a distant time" (4). Both the Yemenite and the young man subvert the gendered social norms by engaging with Fatma and respecting her will to be left alone.

Though Alem offers different representations of men, her novel is mainly focused on women and their world, particularly on the now-forgotten powers of older generations of women. In contrast with Fatma's confusion and her sexual oppression, her grandmother's human and nonhuman relations endow her with a freedom that Fatma's modern existence does not allow her. Alem insinuates her preference for these modes of being through the novel's structure. Therefore, instead of focusing on Fatma's wedding in the chapter entitled "Her Wedding Night," Alem relates the story of the legendary grandmother, Shumla, who celebrates everything Fatma lacks in her marriage, and for whom the erotic leads to invigorating possibilities. The stories Fatma

${ }^{5}$ The only two other times that Fatma left her house were when her father was sick and the second to attend his funeral. 
has heard about her grandmother reveal a woman who understood and experienced the role of desire in empowering women and, therefore, urged other women to do the same.

\section{Celebrating the Grandmother Figure: The Human, Natural and Supernatural}

Fatma is a celebration of an older generation of women who were not cut off from deep feelings and inner knowledge. Therefore, they possessed abilities that are lost to women today-but that can still be intergenerationally transmitted through the erotic. Alem uses various fantastic elements and folk myths to capture Shulma's powers. In the novel, we learn that Shumla was taken away from the natural world that she loved when her family left their tribal home and moved to Mecca. This immigration cut her from the freedom of movement to "the cagelike rooms of her one-story house." However, instead of getting frustrated, she replaced her lost environment with her connection to her inner world, and she built a community of women around her, whom she taught and inspired to be their natural selves, to speak their minds, and to express their feelings without restraint or fear (7). She gave the young women advice that emphasized the importance of sex and sexuality and of unblocking "passageways of love" (8).

In addition to her uninhibited spirit and her ability to draw the best in people around her, Alem describes Shumla as someone who "would sit down and mix her magical leaves and powders" to help women who experienced problems with their love lives. Expertly, "her potions never failed to purify the heart and other vital organs." With the power of words and herbs, women in Shumla's life were not objects of desire, but subjects with the ability to control men's passions. It is vital, she told the young women, to "never entertain lovers when your organs are sluggish. Because this will make a poor impression and weaken his desire." Female eroticism is therefore presented as a weapon that women can take advantage of (8). Stressing on the empowering role of the erotic in women's lives through the depiction of these gatherings, Alem revises and politicizes what a community of women means, and what occurs in such meetings.

This extraordinary passion for life that Shumla and other women in her family enjoy also gives them a legendary longevity and multiple marriages. Fatma recalls how Shumla "had lived...long enough, at least, to witness the passing of every man in the family: twelve brothers, thirty uncles, hundreds of cousins, and the dozens of husbands she kept marrying" (6). This desire always leaves Fatma wondering about the source of passion for life that "rages" in women like her grandmother, who were mostly confined to their rooms due to their advanced age, hardly ever rising from their beds on the floor (7). Fatma therefore conveys to readers that the appearance of confinement of women in the past was an illusion. Instead, they lived liberated lives behind closed doors that Alem's characters are offering us a chance to learn about.

The novel reveals that Shumla had her son and Fatma's father, Mansoor, "when she was, by conservative estimates, a hundred fifty years old" (6). When the son was twenty, she married him off to a friend of hers, who was seventy and who died giving birth to Fatma at the age of one hundred (6). The world Shumla reigned over before moving to Mecca can be described as a matriarchal utopia, where the mother occupies the center of the symbolic order instead of the father. In this system, the reversal of gender roles is commonplace, hence Shumla's marrying her son off to a much older woman. Typically, in female utopias, men are excluded and 
reversed gender roles are presented as the new norm. However, there is no evidence that it is the case in Fatma: men are not excluded, more traditional forms of marriage are still possible, and traditional gender roles persist. For example, women are still considered nurturers, as is implied by the name Shumla gives to her granddaughter, Fatma, which means "The Nurturer' or 'Nurse' for short" (7).

It is legitimate to conclude, then, that Shumla's community reclaims and celebrates aspects associated with the feminine, rather than simply reversing the gender hierarchy. In the process, this reclamation blurs the existing hierarchy. Fatma's ascension into a state similar to that of her grandmother, I will later show, similarly distorts hierarchical binaries. First however, as the next section of this paper illustrates, Fatma has to become aware of and embrace her own womanhood and inner self, as Shumla did in the past. Although Fatma exhibits traits similar to her grandmother before her transformation, as can be sensed from the stories she recalls about her, she only becomes like Shumla and more conscious of her grandmother's character and stories after she embarks on her inner journey. I will argue shortly that Fatma's self-knowledge encompasses a knowledge of her female ancestry, as it manifests through art and story-telling.

Furthermore, Shumla's love of life does not equate a fear a death, but an embrace of it as well. In fact, the grandmother is familiar with death being close to her. She declares to her female friends that Ezrael, the angel of death, sleeps under her bed (7). When he leaves, she follows him because she cannot bear to see him go, and that is how she dies. That Shumla is neither afraid of sexuality nor of death is not coincidental. Anzaldúa argues that humans fear the supernatural, both in its "undivine (the animal impulses such as sexuality [and] the unconscious...) and...divine (the superhuman, the god in us)" forms (17). In other words, a woman who has established a very close connection to the natural and the supernatural world is neither afraid of animal impulses nor of human mortality.

The grandmother is aware of her approaching death, and she begins to fast on honey. On the seventh night she follows the angel of death, the neighbors find her "sitting regally in the crotch of a nabk tree looking toward the horizon, toward the great mountains of her homeland-" the mountains of Shummer (9). This image points to the Arabian Peninsula's folk history, where these mountains symbolize star-crossed lovers. They too are a reminder of this connection between the natural and the human worlds. From its beginning to its end, I argue, Shumla's life revolves around love - the romantic and the spiritual. Again, this narrative invokes the depth of the connection between Shumla and the natural world, which only grows stronger after her death. Not only is she buried completely dressed in green, but when the neighbors cover her corpse with stone slabs, the scent of the acacia, which exuded from her earlier, "thicken[s]" (9). And as her human elements died, another part of her lives on in nature. In Shumla's fantastic world, then, the hierarchy of humans over their natural environment is undermined, as people have a lot to learn from nature. Shumla's sexual knowledge, for example, draws extensively on the nonhuman world: "Animals use their instincts to sanctify the earth with their breath and sweat and pee - whatever has the power to mark the soil and tweak its interest," she tells the other women; "It's no different with you and your partners" (8). Here, we can interpret nature's unity with and power over the human world through the concept of "the numinous," which Chris Brawley defines as the elements in the natural world, the human being, or their union that inspire "a religious feeling of awe, which is the core of all major religious traditions" (5-6). Writers depict the numinous as a more 
humble and honoring view of nature, one that resembles religious worship (6). In Alem's novel, Shumla's relationship with nature and the supernatural is infused with a particular religious tradition - Sufism. Indeed, Shumla's acceptance of death is in-line with Islamic mysticism. In Sufism, it is believed that Sufi saints exude fragrance after their death as a sign of their high spiritual status. In the next section, I show how the fantastic is linked with Sufi images to follow Fatma's own transformation to a woman with powers similar to Shumla's.

\section{The Inner Journey: Fatma as a Sufi Disciple}

Like her grandmother, Fatma senses a connection to the natural world - a feeling that becomes stronger after being bitten by the snake. When she first thinks about her upcoming wedding to the young man her father chooses for her, she compares herself to bees: "Little Nurse Fatma, descendant of the Queen of Longevity, was ready to become a bee in the hive" (10). Shortly after that, she thinks of herself as "a flesheating flower," or "an animal brimming with energy" (12). Noticeably, these metaphors are derived from the erotic feelings Fatma is experiencing. Like her grandmother, who taught her about love and the power of feeling, she is ready to feel deeply.

I argue that the role of the erotic in Fatma's life, however, does not stop at the level of language and metaphors, but proves more transformative as it expands her powers of perception and intuition. As with Shumla's story, transformation is marked by magical elements. In her kitchen, Fatma touches the decorations of The Seven Heavens inlaid with silver half-human half-bird knights on the brass urn there. The knights come to life at her tender touch, making her hands and cheeks feel warm. The awoken images roar with "war cries and shrieks of joy" (12). She touches them again and feels "impossibly alive" (12). Anticipating the role of the erotic in expanding her powers, she observes that "the animal part of her would spring to life and her inner self would be revealed" (13). However, having not experienced them fully, she is still speaking from a theoretical positioning. Fatma still lacks a full understanding of the nature of this transformation, which is reflected in her paradoxical ideas.

Fatma's inner journey of discovery and connecting with her erotic powers result in a new identity with no fixed borders between her human and non-human selves. This developed identity is first foreshadowed earlier in the novel, when her near-death experience blurs the distinction between multiple binaries, such as life and death and the human and nonhuman. While Sajir and her father expect her to die rapidly, she lives and enters a phase they cannot fathom: they are unable tell whether she was dead or alive (20). She then becomes something "between what was human and some other, shocking sort of existence" (22). Soon after that, she is situated between an animal, a plant (musk), and a woman (25). I suggest here that this transcendence of hierarchies and restrictions is symbolized by the dropping of the letter "i" from the Arabic official version of Fatma's name, "Fatima," which signals the elimination of the super ego.

After the snakebite, Fatma's perception expands further with the employment of her inner senses, leading to new heightened insight. She becomes able to see through the souls of things and people, including her husband. With one look, "his heart and soul opened before her like a book. The vision was so nakedly clear 
that she had to look away to leave him some privacy." Indeed, Fatma's looking into Sajir's soul reveals a crippling fear that prevents him from doing the same: "He was being held by nameless enemy, a monster" (27). Sajir's lack of inner understanding results in cutting him off from people and other worlds. Therefore, we hardly see him talk to anyone, and the more he fails to understand Fatma's transformations, the more distant he grows from her and others. Predictably perhaps, Sajir considers Fatma as evil and poisonous, as if she is a real snake. He even warns her not to get close to him because he is sure that a single scratch from her could kill a man - "the woman was that poisonous" (28). As with Anzaldúa's argument, Fatma is linked to the undivine and inspires fear in her husband (17). Still, Sajir does believe that snakes would give him power as well: the power of a prolonged life. He bathes in the water he uses to breed nonpoisonous snakes (29), yet, no "matter how powerful the snake water" is, he remains untransformed (30). Unlike Sajir, who tries to force his power on his snakes without much success, Fatma is able now to control them through nurturing - she being the Nurturer, as her name means. In the end, seeing her success, Sajir surrenders his power to her, and accepts having her in charge of handling the snakes, which become infatuated by her. As a result, the husband feels relief and a peaceful surrender (26), suggesting that he has let go of a heavy burden of trying to control his feelings, his life and his wife.

I read Fatma as analogous to a Sufi disciple whose transcendent knowledge progresses along the spiritual path. I propose that, like a Sufi, she advances from the ability to see through things to the ability to see without looking, or the "art of blindness." Interestingly though, she learns this art from observing the shadows of serpents. The art itself reverses the darkness/light binary, as darkness is described as the better medium for human perception, thus questioning assumptions on enlightenment and traditional practices of spirituality. Her pursuit of this art is reminiscent of the conscious pursuit of self-accomplishment and perfection in our actions, perception, and feelings that, according to Lorde, can result from the power of the erotic. This new/old way of seeing leads to deeper connections, as it allows her to live in union with unknowable creatures (26), underscoring again the correlation between self-knowledge and connecting with others.

The ultimate goal of the Sufi path is losing oneself in Allah, the ultimate Truth or Light. Correspondingly, with her newly developed inner senses, Fatma can now journey to the origin of the self and life. Her first stop in this return journey is the restoration of her girlhood's creative imagination, but with more power that can make the inanimate come alive. She becomes capable of turning a shadow into Noor, the half-lion/half-human flag holder of her girlhood that was drawn on her father's brass urn (28). The incident happens when she notices a particular shadow that is shaped like a human body, but with a featureless face. She then spends several nights sitting next to it until it comes to life, half of it taking the shape of Noor with its lion-head, and the other half looking like a serpent, similar to the new Fatma who now has many of the snakes' powers (29). Noor, then, stands for her childhood innocent and original creative self as well as the newly empowered Fatma. Additionally, with his name meaning light (which is both a male's and a female's name in Arabic), Noor guides Fatma further down the marginalized but empowering paths and ways of seeing, knowing, and speaking back to the origin of things - the transcendent. He is her spiritual guide, which makes him reminiscent of the Sufi master, who guides his/her disciples along the spiritual path. The fact that he is linked to her childhood companion implies another Islamic notion about spirituality - that it is innate. 
Also reminiscent of the Sufi notion that Allah's light is the source of life, Fatma returns to a similar source, "the musical river," which becomes her obsession since it "had the power to penetrate the surface of living things and tap their source of energy, changing everything about them" (36). The river, which emits a musical light, is also significant for its music, which in Sufism stands for the harmony of the world and helps us return to its source. Similar to Sufism as well, Fatma comes to believe that, through beauty and power, everything is a reflection and an echo of the original light and music. The world becomes a creative process: "Fatma could sense the shifting of the mountains, their inching along from eon to eon. Her head spun with the music of it. All things - every creature, every object in the world-were merely shadows cast by the musical light [...] dancing from the specks [of the snakes]. The music and the light-were real [...] Everything else was an ephemeral partner in this dance" (37). This dance of the world echoes the Sufi dance that represents the spiritual ascent to divine love.

Significantly, the musical river is where Sajir's snakes swim (36). Therefore, it is the snakes' water that is the source of the transcendent energy, light, and music, as well as the erotic. Alem thus implies that the transcendent and the erotic are linked. Indeed, Fatma learns that the river is also the origin of humanity since people were born from its music and light, carrying "its tones and harmonic structure in their blood" (36). Fatma's continuous aspiration propels her further to seek this higher harmonious realm, the origin. Learning from the snakes again, she "sat alone far into the night, surrounded by their endless inchoate writhing, trying to achieve the state of blindness in which her body would begin to sink in the musical river" (36). The image of Fatma finally swimming in the musical river clearly signifies a rebirth and a return to the source where flesh and soul are one. Her body too starts to show visible marks that reflect her inner transformation, as "a thin line of dark blue fringed with wings of silver" appears on her face and moves along her body, creating more images as it moves (37-8).

With the changes happening to Fatma, and as she gains powers akin to those of Shumla, the first activity she engages in after her symbolic rebirth is art. Fatma begins to inscribe hers and her grandmother's stories by embroidering them on her gown. She does that though not without Noor's help, who "took a great interest in every twist of the tale Fatma was telling with her embroidery; he even directed her stitches" (46). Here again, unlike their symbolism in the Arab and Judeo-Christian traditions, the snake and women in Fatma are not responsible for the fall, but rather for the return to the origin. Furthermore, the association of snakes with water and writing suggests the need for the story of origin to be reborn, recreated and rewritten based on this new - or reclaimed - symbolism. Fatma, then, has to learn new modes of perception and being before she can speak and write her story, or even before she could read.

Importantly too, the return to the original self also undermines the binaries of gender and sex. This return is foreshadowed early in the novel, as the snake that bites Fatma is genderless (24). Furthermore, Noor, whose name is both masculine and feminine, teaches her the importance of blurring these distinctions. When she tries to understand and identify him better by asking him about traditional identity signifiers, such as his language and gender, he replies: 
What difference does it make? [...] What is a man? A woman? What are you? Why does it matter to you? All you have to do is follow me. You'll arrive at your own conclusions [...] You assume there is a barrier between the sexes. There is no barrier. You will become all sexes. In the end, every creature, every being will drop its mask and simply be itself-the one self (32).

Explaining to Fatma why he needs to leave every time it is daylight, he says: "Daylight helps to make a shadow clear [...] But sometimes it feels better to be vague, without sharp edges" (30). Whereas daylight makes his gender identity visible, Noor prefers to stay in the dark and live as a genderless self. The dark therefore symbolizes a time when the self is not confined to specific identities or to hierarchies. It provides people and spirits alike with the chance to live free of human constraints and to be in unity with the transcendent light.

In conclusion, I view Alem as a mythopoeic writer. A mythopoeic writer attempts "to recreate [...] a new mythology in order to infuse readers with the sense of the transcendent [by] employing fantasy as a subversive mode of literature to revise our perceptions of the natural world; and the distinguishing feature of these authors is going to be an inculcation of a certain religious or mystical 'feeling' of the numinous in the reader" (Brawley 9). Indeed, Alem invites us to look at the natural world and our interconnectedness in a spiritual way. In several interviews with her, Alem refers to the role of her extensive reading in classical Arabic literature and the stories she hears from pilgrims who flock Mecca each year in giving inspiration to her literary experience (Porter 33). These influences are evident in Fatma, where Alem not only questions our ideas about the erotic, but also presents us with new ways of experiencing the world and creating an alternate reality. These new modes of perception are women-centered, challenging and transcending the limitations and repressions of the novel's contemporary period through the reclamation of the inner self. The journey that Fatma embarks on and the life of her grandmother before are infused with elements of the fantastic and a Sufi sensibility, which proposes that embracing the inner self can eventually lead to the divine. Repressing the erotic, on the other hand, can result in the loss of intimate relations and the deterioration of the social self, but also in a disconnection with the spiritual and with hidden fantastic powers that can be within our reach. 
Abu Yahya, Ahmad Isma'il. Al-Hayyah fi al-turatha al-'Arabi. Beirut: al-Matba'ah al-'Asriyah, 1997.

Alem, Raja. Fatma. Syracuse: Syracuse University Press, 2002.

Anzaldúa, Gloria. Borderlands/La Frontera: The New Mestiza. San Francisco: aunt lute books, 1987.

Bordo, Susan. "The Body and the Reproduction of Femininity." Writing on the Body: Female Embodiment and Feminist Theory. Eds. Katie Conboy, Nadia Medina, and Sarah Stanbury. New York: Columbia University Press, 1997. 90-110.

Brawley, Chris. Nature and the Numinous in Mythopoeic Fantasy Literature. Jefferson: McFarlan \& Company, Inc., Publishers, 1987.

D'hean, Theo L. "Magic Realism and Postmodernism: Decentering Privileged Centers." Magic Realism: Theory, History, Community. Ed. Lois Parkinson Zamora and Wendy B. Faris. Durham: Duke University Press, 1995. 191-208.

Foucault, Michel. Discipline and Punish: The Birth of the Prison. New York: Vintage, 1979.

Hafez, Sabry. "Women's Narrative in Modern Arabic Literature." Love and Sexuality in Modern Arabic Literature. Eds. Roger Allen, Hilary Kilpatrick, and Ed de Moor. London: Saqi Books, 1995.

Henitiuk, Valerie. "Step Into My Parlour: Magic Realism and the Creation of a Feminist Space." Canadian Review of Comparative Literature (June 2003): 410-27.

Irigaray, Luce. This Sex Which is Not One, trans. Catherine Porter with Carolun Burke. Ithaca: Cornell University Press, 1985.

Jackson, Rosemary. Fantasy: The Literature of Subversion. New York: Routledge, 1981.

Lorde, Audre. "Uses of the Erotic." Weaving the Visions: New Patterns in Feminist Spirituality. Eds. Judith Plaskow and Carol Christ. San Francisco: Harper, 1989. 208-213.

Porter, Venetia and Henry Hemming. Edge of Arabia: Contemporary Art from Saudi Arabia. Paris: BoothClibborn Editions, 2005.

Showalter, Elaine. Investing Herself: Claiming a Feminist Intellectual Heritage. New York: Scribner, 2001.

Walker, Alice. In Search of Our Mothers' Gardens: Womanist Prose. San Diego: Harcourt Brace Jovanovich, 1983. 